\title{
XIII. On the calculation of the illuminating-power of hydrocarbons and their mixtures
}

\section{R. H. M. Bosanquet F.R.S.}

To cite this article: R. H. M. Bosanquet F.R.S. (1892) XIII. On the calculation of the illuminatingpower of hydrocarbons and their mixtures, Philosophical Magazine Series 5, 34:206, 120-130, DOI: $10.1080 / 14786449208620172$

To link to this article: http://dx.doi.org/10.1080/14786449208620172

曲 Published online: 08 May 2009.

Submit your article to this journal $[\pi$

Џ Article views: 2

Q View related articles $\square$ 
The weight of barium carbonate (witherite) used was .9976 .

The weight after the passage of dried hydrochloric-acid gas was .9984 ,

which shows an increased weight of $\cdot 0008$,

or a percentage increase in weight of $\cdot 08$,

whereas the theoretical increase is 14.7 per cent.

Thus the action of dried hydrochloric-acid gas on witherite is nearly double the amount of its action on Iceland spar.

The specimen of witherite used was fairly pure, but in performing further experiments on the carbonate of barium the precipitated pure carbonate will be used. Incidentally it was noticed that the dried gas had no action upon cellulose, whereas a moistened filter-paper placed in the current of the gas became rapidly converted into a gum-like mass which was probably hydrocellulose.

In conclusion, we wish to point out that the variations in weight which we observed were so minute that no definite assertion can be made of an action having taken place; and the slight variations observed may be due to experimental errors, and to the imprisonment or entanglement of the molecules of hydrochloric-acid gas amongst the finely-divided particles of the Iceland spar or witherite.

We propose to repeat and extend the investigations on these and other carbonates, using greater weights of the substances experimented upon, longer times of exposure of these substances to the action of the gas, and more elaborate precautions to ensure the absence of maisture.

XIII. On the Calculation of the Illuminating-Power of Hydrocarbons and their Mixtures. By R. H. M. BosanQUET, F.R.S.*

W HILE reading recently the work of Percy Frankland $\dagger$ on the illuminating-power of gases, the following considerations suggested themselves. In considering mixtures of marsh-gas with ethylene, \&c., it is observed by $P$. Frankland that such mixtures give a greater illuminating effect than mixtures with hydrogen. The marsh-gas is regarded simply as a diluent, and the explanation of its greater power is sought in the greater amount of heat which

* Communicated by the Author.

+ Chemical Journal, 1884-85. 
it produces (Chem. Journ. 1884, p. 38.) It occurred to me at once that the carbon of the marsb-gas is present, and ought not to be neglected. In fact it certainly has an illuminating value, as has been shown by P. Frankland himself, who found it (l.c.p. 3y) to have an illuminating-power of several candles. I cannot therefore think that the carbon in the marsh-gas should be neglected. If we regard the carbon in flame as being in a sense in solution in the hydrogen, until it is precipitated in the luminous form, it is clear that all the carbon present must count.

This consideration led me to a method of representing the connexion between illuminating-power and composition, which depends primarily on the assumption that the illuminating-power is a function of the ratio of carbon to hydrogen. It seemed also probable that the carbon density might be involved.

The $\mathrm{C} / \mathrm{H}$ ratio employed might be more correctly written $m / n$, where $\mathrm{C}_{n} \mathrm{H}_{n}$ is considered. But it is perhaps more convenient to speak of it as the $\mathrm{C} / \mathrm{H}$ ratio. It will be represented by $x$, and measured along the horizontal axis. The candle-power is represented by $y$, and measured along the vertical axis.

First I took the series of mixtures of ethylene and hydrogen which is given at Chem. Journ. 1884, p. 34. The C/H ratio was calculated, also the carbon density. The table then assumes the following form :-

Ethylene and Hydrogen.

\begin{tabular}{|c|c|c|c|c|c|}
\hline \multicolumn{2}{|c|}{ Per cent. } & \multirow[t]{2}{*}{$\begin{array}{l}\text { Carbon } \\
\text { Density. }\end{array}$} & \multirow{2}{*}{$\frac{\mathrm{C} / \mathrm{H} \text { ratio. }}{x}$} & \multicolumn{2}{|c|}{ C.P. } \\
\hline $\mathrm{C}_{2} \mathrm{H}_{4}$. & $\mathrm{H}_{2}{ }^{*}$. & & & 1)irect. & Indirect. \\
\hline 100 & 0 & 2 & $\cdot 5$ & 68.5 & 65 \\
\hline 77.55 & $22 \cdot 45$ & $1-55$ & $\cdot 437$ & & \\
\hline $68 \cdot 39$ & $31 \cdot 61$ & $1 \cdot 37$ & $\cdot 405$ & & \\
\hline 53.58 & $46 \cdot 42$ & 1.07 & $\cdot 349$ & & \\
\hline $35 \cdot 47$ & $64: 53$ & .709 & .262 & & \\
\hline $26 \cdot 08$ & 73.92 & 522 & $\cdot 207$ & & \\
\hline $13 \cdot 37$ & $86 \cdot 63$ & $\cdot 267$ & $\cdot 118$ & & \\
\hline
\end{tabular}

* I have added the subscript 2 here. It has to be taken count of in the calculations. 
In addition to these we have also from P. Frankland * :-

$$
\begin{aligned}
& \text { Density. } \mathrm{O} / \mathrm{H} \text { ratio. } \quad \text { C.P. } \\
& \text { Ethane, } \mathrm{C}_{2} \mathrm{H}_{6} \quad \ldots \ldots \ldots . .2 \quad 2 \quad \frac{1}{3} \quad 35 \\
& \text { Propane, } \mathrm{C}_{3} \mathrm{H}_{8} \ldots \ldots \ldots . . \quad 3 \quad \quad .375 \quad 54
\end{aligned}
$$

These were all laid down as on the figure. These mixtures are shown by round black points; ethane and propane by oblique crosses, $x$.

The general course of the mixtures can be roughly represented by a straight line. This, however, passes below the ethylene point at the top. All the mixture lines obtained later agree in placing the ethylene point at a C.P. lower than $68^{\circ} 5$, and we shall assume that 65 is the point through which the line should be drawn.

The point representing ethane lies on the right of the line, below it, and near it at a point whose carbon density is about 1, that of ethane being 2. The point for propane is on the other side of the line, its carbon density being 3 . It appears then that, so far as mixtures are concerned, the carbon density has no direct influence. The influence of carbon density on pure substances will be treated later.

Next we proceed to consider the mixtures of ethylene and marsh-gas given by P. Frankland, $l$. $c$. The carbon density

\begin{tabular}{|c|c|c|c|}
\hline $\mathrm{C}_{2} \mathrm{H}_{4}$. & $\mathrm{CH}_{4}$. & $\underset{x}{\mathrm{C} / \mathrm{H} \text { ratio. }}$ & $\begin{array}{c}\text { C.P. } \\
y\end{array}$ \\
\hline $85 \cdot 67$ & $14 \cdot 33$ & $\cdot 4642$ & 57.91 \\
\hline 69.09 & 30.91 & $\cdot 4227$ & $47 \cdot 88$ \\
\hline 57.74 & $42 \cdot 26$ & $\cdot 3943$ & 40.42 \\
\hline $35-90$ & $64 \cdot 10$ & $\cdot 3397$ & $33 \cdot 17$ \\
\hline 13.00 & $87 \cdot 00$ & $\cdot 2825$ & $19 \cdot 35$ \\
\hline 7.87 & $92 \cdot 13$ & 2697 & $17 \cdot 59$ \\
\hline
\end{tabular}
is now omitted.

Ethylene and Marsh-Gas.

These are also laid down on the figure, being represented by small circles with dots in the centre. It will be seen that they lie pretty closely upon a straight line drawn from the point which represents ethylene, taking the C.P. as 65, and meeting the $x$ axis, or disilluminate line, at $x=\cdot 19$ nearly. The last two terms of the above series afford an explanation which

* Chem. Journ. 1885, p. 238. 
is crucial with respect to this method. The percentage of ethylene in the last but one is nearly twice that in the last, yet the C.P. differs but little. The explanation is that here the carbon of the ethylene is added to the considerable quantity of earbon already present in the form of marsh-gas.

I now come to a point of some difficulty. If this straight line represents the behaviour of mixtures of ethylene and marsh-gas as well as it appears to do, it should also represent the case of marsh-gas itself. But seeking* the point in the line corresponding to $x=\cdot 25$, we find $y=12 \cdot 4$. This indicates what we may call a theoretical candle-power of 12.4 for marsh-gas.

Now it is certain that marsh-gas does possess illuminatingpower. P. Frankland states that marsh-gas determined in the Referee's burner gives a power of "several candles" $t$. Also Wright has determined its lighting-power, which he makes about 5 candles (Chem. Journ. 1885, p. 202).

But admitting that the gas has some illuminating-power, it will not be generally thought that this can amount to 12 candles.

There are two views which may be taken. The one, that the straight line fails here to represent the properties of the mixture when the ethylene vanishes. This is quite possible. If so, a curved tail will have to be added to represent the pure marsh-gas, when it has been determined exactly what the candle-power is that it can be supposed to have.

The other view, to which I incline, is that our methods are not adapted for the measurement of illuminating-powers of small intensity; and that for the present we must treat such cases with reserve.

Turn back for a moment to the series of mixtures of ethylene and hydrogen. The lowest point falls considerably below a line drawn through the two next above. Now it may be that the illuminating value shown by this lowest point is too low for the reason above suggested, the inadequacy of the methods for very low powers. If so, the real course of the hydrogen mix tures may be substantially different from that shown.

* The equation was formed to the line passing through the first and last but one of the mixture points. This line gave.

$$
\begin{array}{ccc}
\text { Ethylene } \ldots \ldots \ldots \ldots \ldots \ldots \ldots & 65.5 \\
\text { Marsh-gas } \ldots \ldots \ldots \ldots \ldots & 12 \cdot 4
\end{array}
$$

I do not enter at length into the discussion of the ethylene values; but this was regarded as the most important of the values employed.

$\dagger$ Chem. Journ. 1884, p. 39. 
Again, lines drawn through the points representing the two sets of mixtures, excluding the ethylene point, meet at a lower C.P. than that given by the direct determination of ethylene.

A value of 65 C.P. for ethylene fits both series much better than the direct number $68^{\circ} 5$, and would also fit better combinations which occur later.

I therefore adopt the number 65. The question is here not so much whether this is the exact C.P. of ethylene, as whether the mixtures behave as if it were so. This they appear to do.

The remaining mixtures are all made with " disilluminated gas" of the Gas Light and Coke Company. The analysis of this gas is given at Chem. Journ. 1884, p. 193. The C.P. of the original gas is 16. I assumed at first that the "disilluminating" was equivalent to the removal of the heavy hydrocarbons, the proportions of the remaining marsh-gas and hydrogen giving the value of $x$. I did not take any account of the presence of the other gases, which include about 6 p. c. of nitrogen and 4 p. c. of carbonic oxide.

The percentages of hydrogen and marsh-gas are

$$
\mathrm{H}_{2}=47 \cdot 99, \quad \mathrm{CH}_{4}=37 \cdot 64 \text {. }
$$

From these the $\mathrm{C} / \mathrm{H}$ ratio comes out $x=\cdot 1527$, as obtained direct from the analysis.

Two mixtures were made with this disilluminated gas and ethylene ${ }^{*}$; I have added the values of $x$.

\begin{tabular}{|c|c|c|c|}
\hline $\begin{array}{c}\text { Disilluminated } \\
\text { gas. }\end{array}$ & Ethylene. & $x$ & $\begin{array}{c}\text { C. P. } \\
y\end{array}$ \\
\hline 86.59 & $13 \cdot 41$ & .2224 & 16.84 \\
68.98 & 31.02 & .2992 & 28.40 \\
\hline
\end{tabular}

These points are represented in the figure by upright crosses, + ; a line drawn through them passes below the ethylene point at 65 , and to the left of the calculated disilluminate point $x=\cdot 1527$. It must be remembered that, besides the possibility of imperfect disillumination, the gas contains considerable quantities of nitrogen and carbonic oxide; so that it seems better to derive the disilluminate

* L. c. p. 191. 
point from the actual behaviour of the mixtures than direct from the analysis. The disilluminate point selected is

$$
x=\cdot 1321, y=0 \text {. }
$$

This is the mean of the numbers given by equations of lines drawn from the ethylene point at 65 to the mixture points *.

Two mixtures were also made with disilluminated gas and benzene vapour.

$\begin{array}{lccc}\text { Dis. gas. } & \text { Benzene. } & x & y \\ 96.91 & 3 \cdot 09 & \cdot 21210 & 22 \cdot 92 \\ 96 \cdot 70 & 3 \cdot 30 & .21222 & 24 \cdot 17 \\ & & - & \\ & \text { Mean......... } & \cdot 21216 & \\ & & & 23 \cdot 54\end{array}$

The two points are too close together to draw a line through with any useful result. I have calculated the position of such a line, and it is nearly vertical, which does not correspond at all with other indications. (The illuminating-power of benzene would come out about 1000.) So I have taken the mean of the numbers, and denoted the point by an upright cross of dotted lines.

Through this benzene cross a line is drawn from the disilluminated-gas point, $x=\cdot 1321$. If the various suppositions that are made are at all true, this line at its intersection with $x=1$ should give the C.P. of benzene. This number calculated from the above data is 255 .

It remains only to consider the complete gas of the Gas Light and Coke Co. The percentage and numerical formula of the heavy hydrocarbons are given, so that the value of $\mathrm{C} / \mathrm{H}$ for the whole gas can be obtained. Hence I find

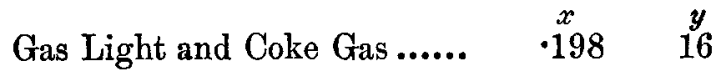

This point is laid down as a dotted oblique cross. $A$ line drawn through this from the disilluminated-gas point $(x=$ -1321) lies fairly between the lines of the benzene mixture and the ethylene mixture. The influence of the nature of the mixture of heavy hydrocarbons thus indicated will be dealt with later.

Let us now turn to the meaning of the lines on the figure. The slope of a line represents a ratio $\Delta y / \Delta x$, the ratio of difference of candle-power to difference of $\mathrm{C} / \mathrm{H}$ ratio. We may regard it as the illuminating value of unit $\mathrm{C} / \mathrm{H}$ difference, and shall speak of it as the illuminating ratio.

* I have not succeeded in representing this with great correctness on the small figure. That conveys a general idea, but the numbers have in all cases been worked out by the equations. 
$126 \mathrm{Mr}$. Bosanquet on the Illuminating-Power

We infer from the examples which have been considered in detail, that (subject to exceptions connected with low

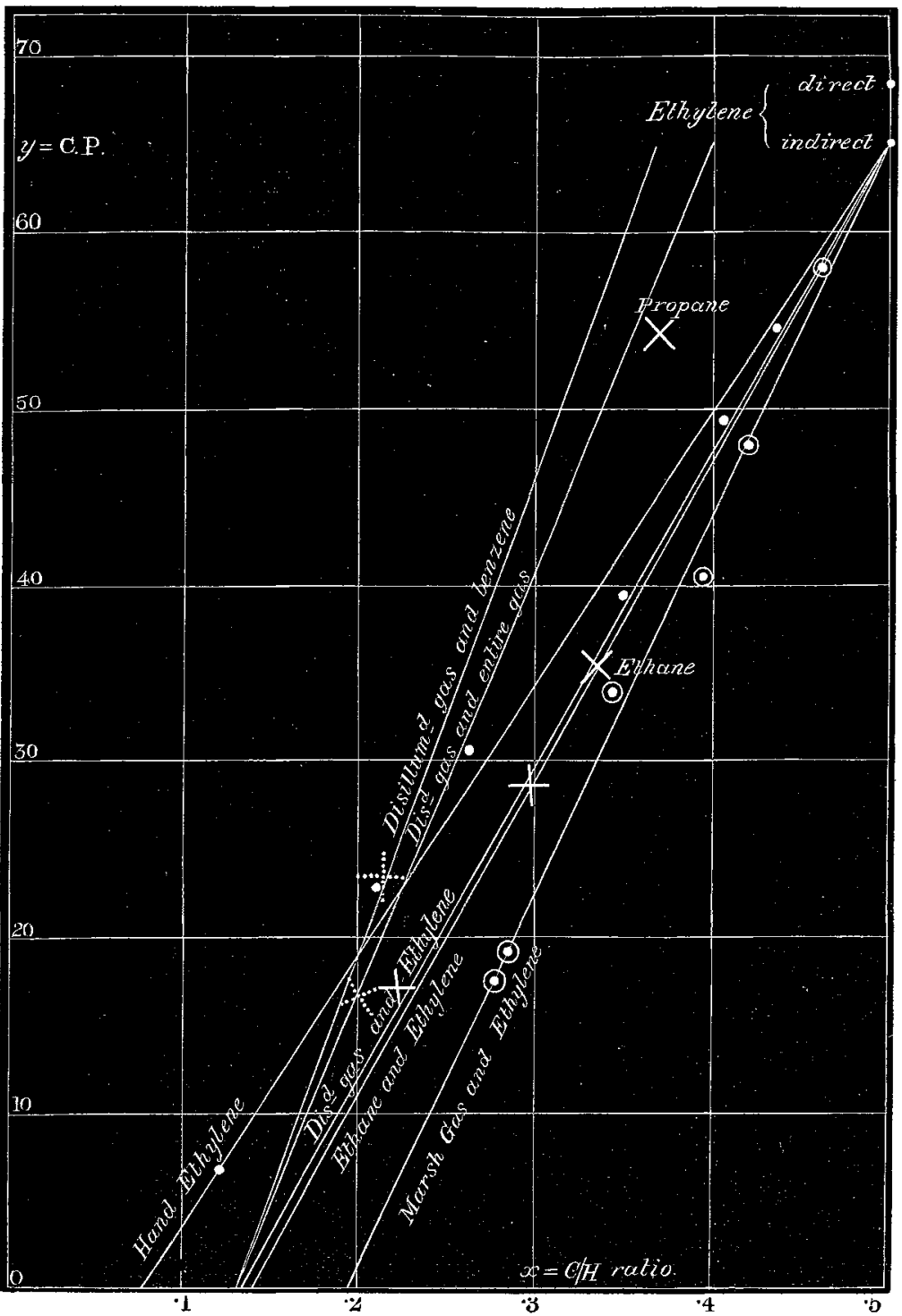

illuminating values), the illuminating ratio is constant for mixtures of two definite substances. The marsh-gas-ethylene 
mixtures form the best example of this. They all obey the law pretty closely except marsh-gas itself, which has been considered. Supposing, for the sake of an example, that we admit the "theoretical value" 12.4 C.P. for marsh-gas, the illuminating ratio may be obtained at once by taking $\Delta y$ and $\Delta x$ for the two substances.

$$
\begin{aligned}
& \Delta y=65-12 \cdot 4=52 \cdot 6 \\
& \Delta x=\cdot 5-\cdot 25=\cdot 25 .
\end{aligned}
$$

Illuminating ratio $=\Delta y / \Delta x=210 \cdot 4$.

Then this ratio is the same or nearly so, from whatever pair of the mixtures it is derived.

I will now employ these principles to calculate the illuminating-power of the Gas Light Coke gas from its analysis, as given in Chem. Journal, 1884, p. 193, as far as our present materials permit.

I take from the analysis :-

Percentage of heavy hydrocarbons ...... $4 \cdot 41$

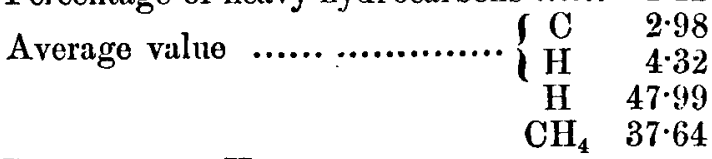

The $\mathrm{H}$ is of course $\mathrm{H}_{2}$.

$\mathrm{CH}_{4} \quad 37 \cdot 64$

From this I calculate,

For heavy hydrocarbons ............. $x=\quad \cdot 690$

For entire gas ........................... 198

The disilluminate point is determined as

before described by the two mixtures of $\} \cdot 132$

disilluminate gas with ethylene ............

$$
\begin{array}{lr}
\text { For Ethylene......... } & \text { C. P. }=\begin{array}{r}
65 \\
\text { For Benzene ......... }
\end{array}
\end{array}
$$

These are the data.

First form the equation of the line joining the ethylene and benzene points.

The equation is,

$$
\begin{array}{crl}
x^{\prime \prime}=1 & y^{\prime \prime}=255 & \text { Benzene, } \\
x^{\prime}=-5 & y^{\prime}=65 & \text { Ethylene. }
\end{array}
$$

$$
y-65=(x-\cdot 5) \frac{255-65}{1-\cdot 5} \text {. }
$$

In this put $x=\cdot 69$, and we get for the C.P. of the heavy hydrocarbons $y=137$. Combining this with the disilluminate 
point, we get a line which represents all mixtures of these hydrocarbons with the disilluminated gas.

Equation to line through,

$$
x^{\prime \prime}=\cdot 69 y^{\prime \prime}=137 \text { hydrocarbon mixture, }
$$

and

$$
x^{\prime}=\cdot 132 \quad y^{\prime}=0 \quad \text { disilluminated gas }
$$

is

$$
y=(x-132) \frac{137}{\cdot 69-\cdot 132} \text {. }
$$

In this put $x=\cdot 198$; and we have for the C.P. of the entire gas, $y=16 \cdot 2$.

So that we have determined the illuminating-power within 2 tenths of a candle of the real value 16, from the data given.

Of course there are many things in this process which require further attention. Chiefly the influence of the diluent constituents, which are present in small quantity, and the assumption that the heavy hydrocarbons are entirely composed of ethylene and benzene, which cannot be entirely true, though it may be so very nearly, according to the analysis.

We proceed to consider the question of the carbon density of pure substances. It appears at once evident that the representative points surround the disilluminate region in such a way that the angles with the $x$ axis made by lines radiating from that region to the points are larger for substances of greater carbon density, and smaller for those of less. The first question is, what point is to be assumed as centre? We have the data for determining this only in the case of carbon density $=2$. Drawing a line through ethylene and ethane, and taking ethylene C.P. $=65$ we have $x=\cdot 138$ at the intersection with the $x$ axis. In the absence of further information we assume that this point represents what may be called the disilluminate hydrocarbon centre.

It appears probable that the illuminating ratio is formed by the addition of differences which correspond to successive units of carbon density.

The first unit is a difficulty, as we are uncertain as to the C.P. of marsh-gas. Perhaps it is best to leave this out of consideration at first, and arrange the number in accordance with the rest of the series, the law of the whole being as far as possible continuous. The values of the illuminating ratios formed by lines drawn to $\cdot 138,0$, are as follows :- 
Illuminating Ratios from Disilluminate Hydrocarbon Point, $\cdot 138,0$.

\begin{tabular}{|c|c|c|c|c|}
\hline $\begin{array}{l}\text { Carbon } \\
\text { density. }\end{array}$ & Substance. & $\begin{array}{c}\text { Experi- } \\
\text { mental } \\
\text { number. }\end{array}$ & $\begin{array}{l}\text { Adjusted } \\
\text { number. }\end{array}$ & $\begin{array}{l}\text { Differences of } \\
\text { successive } \\
\text { terms. }\end{array}$ \\
\hline 1 & Marsh-gas ..... & $\ldots \ldots$ & 108 & \\
\hline 2 & Ethylene & $\frac{65}{\cdot 5-\cdot 138}=180$ & 180 & 72 \\
\hline 3 & Propane........ & $\frac{54}{375-138}=228$ & 228 & 99 \\
\hline 4 & $\ldots \ldots$ & $\ldots \ldots$ & 260 & 04 \\
\hline 5 & $\ldots \ldots$ & $\ldots \ldots$. & $281 \cdot 3$ & \\
\hline 6 & Benzene.......... & $\frac{255}{1-\cdot 138}=295 \cdot 8$ & $295 \cdot 5$ & $14 \cdot 2$ \\
\hline
\end{tabular}

The differences form a geometrical progression, which has the common ratio $2 / 3$, and 108 for the first term. Thus the successive units of carbon density correspond to increments of illuminating ratio in strict geometrical progression, and all the numbers present a continuous law*.

To find the C.P. of any hydrocarbon, as determined by these numbers, we use the equation

$$
y-y^{\prime}=m\left(x-x^{\prime}\right) \text {, where } x^{\prime}=\cdot 138 \text { and } y^{\prime}=0 .
$$

$m$ stands for the illuminating ratio.

Thus to find the value of the C.P. of marsh-gas, as indicated by this scheme, we have

whence

$$
y=108(x-\cdot 138) \text { and } x=\cdot 25,
$$

$$
y=\text { C.P. }=12 \cdot 1 \text {, }
$$

a somewhat lower value than that $(12 \cdot 4)$ previously found from the ethylene mixtures. The agreement is remarkable, considering the entire independence of the two methods.

For another example take tetrane, $\mathrm{C}_{4} \mathrm{H}_{10}$,

$$
\begin{gathered}
y=260(x-\cdot 138) \text {, and } x=\cdot 4, \\
\text { C.P. }=68 ;
\end{gathered}
$$

* The difference 48 was taken as fixed, and the factor found which would bring the benzene number right; it proved to be just 23 . This was then applied to form the first term, which fell into its place.

Phil. Mag. S. 5. Vol, 34. No. 206. July 1892. K 
Yentane, $\quad y=281(x-\cdot 138)$, and $x=\frac{5}{12}=\cdot 417$,

$$
\text { C.P. }=117 \text {. }
$$

In the same way the C.P. of all hydrocarbons up to carbon density 6 can be obtained from the scheme. How far they will prove to be accurate remains to be seen. It must be remeinbered that the number for benzene is a most important element, and that it depends only on the mean of two mixtures, neither of which contained much more than 3 per cent. of benzene.

No doubt the process could be carried further, but more experimental evidence would be desirable first. So far I have taken no account of the presence of mere diluents, such as nitrogen or carbonic acid or oxide.

Experimental determinations of propylene and its homologues, and of the paraffins, or of mixtures of these substances with marsh-gas or disilluminated gas, are commended to those who possess experimental facilities in connexion with the subject. Also more determinations of benzene mixtures are wanted.

I hope shortly to return to the question of diluents, so far as the available material will permit.

\section{Proceedings of Learned Societies.}

GEOLOGICAL SOCIETY.

[Continued from vol. xxxiii. p. 540.]

February 10, 1892.-Sir Archibald Geikie, D.Sc., ILD., F.R.S., President, in the Chair.

THE following communications were read:-

1. "The Raised Beaches, and 'Head' or Rubble Drift of the South of Eagland: their relation to the Valley Drifts and to the Glacial Period ; and on a late Post-Glacial Submergence.-Part I." By Joseph Prestwich, D.C.L., F.R.S., F.G.S.

The author remarks that, besides the subaerial, fluviatile and marine Drifts of the South of England, there is another Drift which is yet unplaced. This he considers to be connected with the 'Head' overlying the Raised Beaches. Of these he describes the distribution, characters, and relations along the South Coast. The 'Head' overlies the beaches, and frequently overlaps them. In the beaches large boulders are found, and marine shells, of which lists for the various localities are given. The 'Head' frequently shows rough stratification of finer and coarser materials. It contains 